\title{
Analysis of the impact of the conclusion of the Collaborative Professional Master's Program on Embraer and ITA.
}

\author{
Paulo Lourencao, Orlando Souza Neto, Flavio Bussamra* and Roberto Gil Silva* \\ Engineering Strategy/Embraer, S J Campos, SP/Brazil \\ E-mail: paulo.lourencao@embraer.com.br, orlando.neto@ embraer.com.br, flaviobu@ita.br, gil@ita.br \\ *Division of Aeronautical Engineering/ITA, SJ Campos, SP/Brazil
}

\begin{abstract}
The creation of Embraer resulted from a long-term investment of the Brazilian Government in developing the necessary conditions for designing and manufacturing airplanes in the country. In each decade after its creation in 1969, Embraer launched a different type of aircraft. In 1999, Embraer launched the program for Regional Jets ranging from 70 -110 passengers, which implied a high demand of new engineers. One alternative to cope with that was the creation of the Professional Master's Program in Aeronautical Engineering in 2002, in partnership with ITA (Aeronautics Institute of Technology). The objective of the program has been to provide specialized knowledge to recently graduated engineers, in order to prepare them to work in multidisciplinary teams in Embraer engineering areas. The collaboration between Embraer and ITA is present from the selection process, through curriculum design up to Master's theses. The objective of this paper is to present results of an evaluation of the impact of the Master's Program on alumni's performance on their work, on the company (technology, process, products, services and patents) and on the Institute. Since 2002, the program has already prepared more than 1400 students. Out of them, more than 800 are still working for Embraer (Feb 2019) and more than 400 have their Master's theses approved. The methodology adopted in this paper consisted in interviews and surveys with former students of the program, their direct supervisors and both their industrial and academic advisors. This paper presents, as results, the most significant contributions both to the company and to ITA.
\end{abstract}

Keywords: Pre-projects, Conceptual Design, Engineering Education

\section{Introduction}

This session initially presents the context of creation of the Technical Center of Aeronautics (CTA), of Aeronautics Institute of Technology (ITA) and Embraer. This is important to understand the conditions that led the creation of the object of analysis of this paper, the Professional Master's Program of ITA in partnership with Embraer, to be conceptualized and implemented.

In continuation, the objective and the structure of the paper are presented.

\subsection{Context}

After the end of World War II, the Brazilian Government decided to create the necessary conditions to design and manufacture airplanes in the country. In addition to national security, the size of the nation and the need of connecting remote areas clearly justified that decision. CTA was conceptualized by prof. Richard H. Smith from the Department of Aeronautical Engineering of the MIT in 1945 [1].

The original plan proposed the creation of a "Technical Center that would consist of two technically autonomous Institutes working under the same coordination: the first for higher technical education and the second for research and cooperation with an aircraft industry that would have both military and commercial aviation branches. According to the original plan, when the Institutes laboratories could deliver a potential product then a plant would be established" [1].

In the 50's, ITA was established as a School of Aeronautical Engineering. In 1954, the Institute of Research and Development (IPD) was created, employing many engineers graduated from ITA. IPD conducted R\&D in many areas such as Aeronautics, Electronics, Materials, Aircraft Systems, and others related to the field. IPD was responsible for the designing and building the "Bandeirante" aircraft that led to the creation of Embraer in 1969 [2].

Since its creation, decade after decade, Embraer has launched new aircraft. Considering commercial aviation only, in the 70's, the company developed the EMB 110 - Bandeirante a turboprop commuter for 18 passengers. In the 80's, Embraer launched Brasilia - a turboprop pressurized aircraft for 30 passengers - its first FAR 25 certified plane. In the 90's, the ERJ 145 - its first Regional jet, and in 1999 Embraer launched the E-Jet 170-190 program, a clean sheet design jet for 70 118 passengers [3].

From 1990 to 1996, the company faced a big crisis that culminated with its privatization in 1994. Due to the crisis, big layoffs took place, reducing the number of employees from more than 11000 to 3200 . 
When the E-Jets 170 -190 program was launched, there was a need of hiring a large number of engineers to cope with the complexity of this new aircraft. The Professional Master's Program in Aeronautical Engineering (PEE) was launched to cope with this challenge [4].

The postsecondary degree system in Brazil is comprised of three levels: Bachelor's, Master's and Doctoral degrees. Typically, undergraduate engineering courses last 5 years, Master's Programs 2 years and Doctoral degree 4 years. The difference between Academic and Professional Master's Programs is that the thesis of the latter could be focused on technology problems instead of science challenges. Also, Professional Master's Programs allow students to be assisted by both academic and industrial advisors.

\subsection{Objective}

The objective of this paper is to present results of an evaluation of the perception of the most important stakeholders on the impact of the Master's Program as a whole on : i) the alumni's performance on their work, ii) the company (technology, process, products, services and patent) and iii) ITA (Research and Education).

The paper is structured as follows: in literature review, some basic concepts related to Case Study Research and Evaluation Methods for assessing the impact of educational programs are presented; in session 3, the current structure of PEE is presented, as well as some data about the program.

\section{Literature Review}

\subsection{Case Study Research}

The case study research method can be used in many circumstances in order to understand their social, political or organizational events in depth. Case studies tend to be more suitable when the understanding of "why" or "how" some phenomena work in certain circumstances, requiring some extensive descriptions. Case studies may also be a combination of both qualitative research and quantitative research [5].

\subsection{Evaluation of Training}

The importance of evaluation of training, or any development program, lies in determining its effectiveness, which can be meaningful for the ones responsible for the program, its clients and its stakeholders. One of the main reasons to evaluate a training program is to gather relevant information on how to improve it. Moreover, it is paramount to acquire some perspective on how it contributes to the company's goals and objectives [6].

Programs can be evaluated in four levels, according to Kirkpatrick [6], which are: 1) Reaction, 2) Learning, 3) Behavior and 4) Results. The first level can be summarized into "customer satisfaction". In other words, it is a measure of how the participant react to it, which may influence their learning throughout the training program in either a positive or a negative way. The second level, Learning, consists in the improvements and changes on the participant skills, attitudes and knowledge after taking the program. The third level, Behavior, is related to the consequence of one's change of behavior due to the conclusion of a training course, which requires some conditions in order for the change to occur. In this sense, it means to check if the participant behaves and is using the attitudes, knowledge and skills developed in the course, in his or her activities. At last, the fourth level, which is the main concern of the present work, is related to the results of one's attendance to a program. It can be noticed by an improvement on quality, decrease of rework, costs, and increase in production [6].

Another way to measure the contribution of training programs is the measurement of the Return on Investment (ROI), whose methodology has been adopted by many organizations in manufacturing, government, educational settings and others. It includes a fifth level of evaluation of training to the previous model developed by Donald Kirkpatrick: 1) Reaction and Planned Action - related to the satisfaction; 2) Learning - related to the learned skills; 3) Application and Implementation - focused on whether the learned content was either applied or not by the participants on their jobs; 4) Business Impact - related to the business impact of the training program; 5) Return on Investment related to the monetary value of the program compared to its costs [7]. Fig. 1 summarizes the approach suggested by the ROI Institute [8].

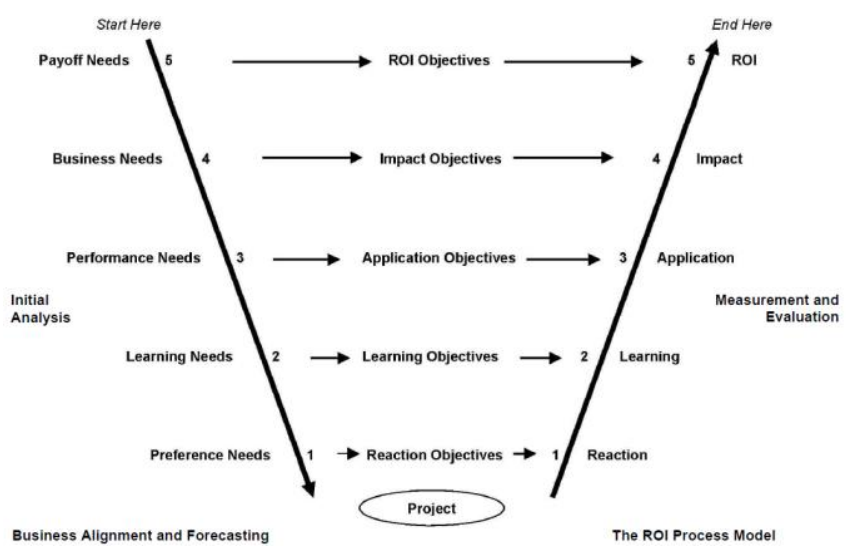

Figure 1 - The ROI Methodology Model. Photo: The ROI Methodology in 10 Easy Steps. (Adapted from [8]).

\section{Master's Program Overview}

The first class of PEE was launched in 2001. Until 2019, the program has already prepared more than 1500 engineers, out of whom more than 900 concluded their Master's theses. Based on an internal report issued in July 2019, more than 500 of the latter are still working in the company.

In fact, PEE is an Embraer's deliberate strategy of attracting, selecting, developing and retaining young engineers from all over Brazil, to get them involved in multidisciplinary teams to develop new aircraft. It is also an effective way of knowledge management, in the sense that experienced engineers, working in the program as instructors and mentors, share their knowledge with the future generations. 


\subsection{Pedagogical Model}

One of the key factors of the success of PEE is the capacity of attracting and selecting talented engineers. The recruitment is done in both websites of ITA and Embraer.

The selection process of future students (adopted by Embraer and ITA) takes into consideration a set of competencies organized in the following categories: Engineering fundamental knowledge, personal skills, interpersonal skills and conceive-design-build-test engineering systems [9]. It comprises three parts.

In the first part, the candidates take an online test to assess their proficiency in English and their competence on handling questions of logic. Over the last five years, the PEE selection process has been able to attract more than 5000 recently graduated candidates from Engineering Schools all over Brazil. This first part brings this number down to 1500 candidates.

The second part in the selection process is a written exam held in more than 10 capitals and cities of several Brazilian states. The exam covers topics usually addressed in the first two years of any undergraduate Engineering course in Brazil. Questions are specially prepared by ITA Faculty, on Calculus, Differential Equations, Physics, Strength of Materials, Fluid Dynamics, Thermodynamics, and Heat Transfer, among other topics. The candidates are also tested in English, Technical Drawing and basic knowledge on Computer Science. From these results, the number of candidates is reduced to 200 .

The third part is composed of interviews and group dynamics, which are held at Embraer facilities in São José dos Campos; ITA professors and Embraer employees are the examiners. Borrowing some ideas from the CDIO Approach [10], candidates are evaluated on their competencies on personal, professional and interpersonal skills. The final result of the selection process is a group of 30 to 40 engineers.

The academic part of the program is comprised of four phases, represented in fig. 2. During the first phase, all the students take the same classes. From ITA, courses are related to basic knowledge on Aeronautical Engineering (Aerodynamics, Performance, Flight Mechanics, Propulsion and Structures), Material and Manufacturing Processes, Control, Integrated Logistic Support and Integrated Product Development. In addition to ITA academic disciplines, the students take a series of Embraer courses: Introduction to Aeronautical Engineering, Introduction to Aircraft Systems, Aviation Business, System Engineering, etc. These Embraer courses are taught by very experienced engineers from the company, as well as recently retired specialists.

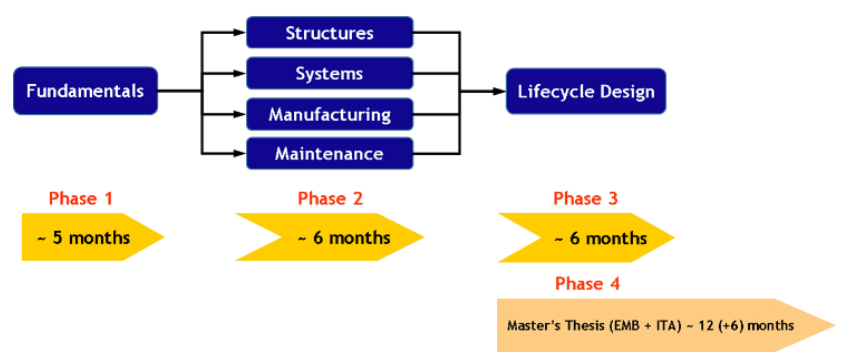

Figure 2 - General Structure of the Professional Master's Program.

In the second phase, students are separated in four tracks, according to their own preferences and the company's needs. On the Structures track, the students learn about Structural Analysis and Design, Fatigue and Fracture Mechanics, Structure Dynamics and Aeroelasticity, and Analysis and Design of Composite Structures. On the Aircraft Systems track, courses address different areas such as Electrical Systems, Communication Navigation and Surveillance, Hydraulic Systems, Modelling and Simulation, and Sensors and Measurement Systems. The Manufacturing track comprises courses on Production Management, Design and Manufacturing of Composite Structures, Modelling and Simulation of Discrete Systems, Manufacturing of Complex Surfaces and Topics in Advanced Manufacturing. Finally, the Maintenance track includes courses on Aircraft Maintenance, RAMS (Reliability, Availability, Maintainability and Safety), e-Maintenance, Reliability Centered Maintenance, Logistics in the Development, Acquisition and Operation of Complex Systems and Modelling and Simulation of Discrete Systems. Still during phase 2, students have to select the theme of their Master's theses, associated with a pair of advisors: academic (ITA) and industrial (Embraer).

The third phase, named by ITA "Industrial Internship", which lasts one semester, is characterized by a "Conceive Design" exercise in which the students are divided into two teams to simulate the Conceptual and Preliminary Design of a new aircraft [11]. The deliverables of each team, during phase 3, are High Level Requirements, Value Proposition, Conceptual Design and Preliminary Design, including Business Case to demonstrate Technical Viability and Economical Feasibility. The real "magic" behind this exercise is that the two teams design and develop a completely new aircraft, with the support of more than 15 mentors from the company and from ITA, see fig. 3. Mentors represent different areas and technologies: Marketing, Lean Development, Project Management, Aerodynamics, Design, CATIA, Structures, Systems, Manufacturing, Maintenance, Interiors, Materials, Product Integrity, Business Plan, etc. Embraer considers this exercise pivotal for social-technical integration of the future engineers.

During the fourth phase, the students have to finalize their Master's theses. Since the company has already hired them at this moment, they have some hours per month set aside for this purpose, which are classified officially as training hours. 


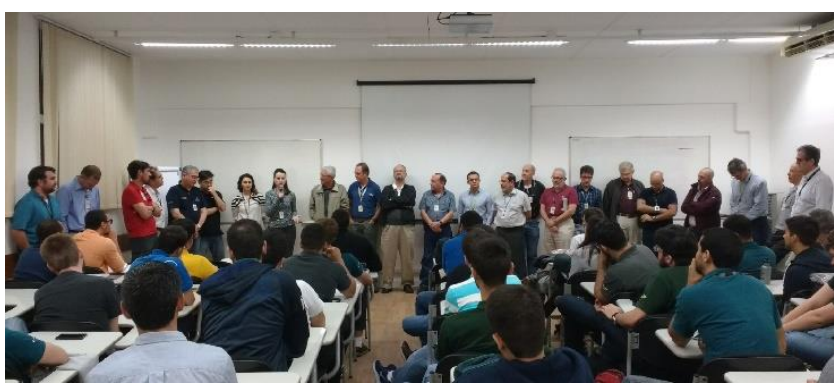

Figure 3-Group of mentors of the Conceive-Design phase of the Professional Master's Program.

\section{Methodology}

This section presents the methodology applied in the current case study research, consisting of face-to-face interviews and online questionnaires involving triads composed of the PEE alumni, their direct supervisors and industrial advisors (see fig. 4). In order to evaluate the impact of the Master's Program conclusion, a case study research was conducted with the classes 22, 23 and 24 of PEE. The survey on the individual perceptions was composed of two parts. The first part consisted in interviews with a focus group of selected students from class 23, their correspondent supervisors and industrial advisors. Four triads were selected to participate in face-to-face, semi-structured interviews.

The objective of this pre-test was to identify the perception of the interviewees on the main contribution of the Master's conclusion on personal aspects, impacts on their work sector of the company and on Embraer as a whole (technology, processes, products, services and patents). During this part, the technology areas, in which the PEE alumni developed their Master's theses, were classified according to ASTERA taxonomy adopted by the European Aeronautics Science Network (EASN) [10].

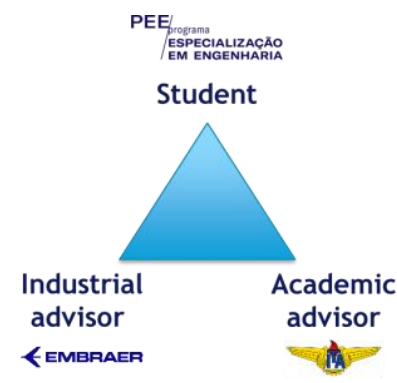

Figure 4: The triad. Photo: the authors.

The pre-test for the interviews contained both open and closed questions. The closed questions followed the Likert scale [5], i.e. the respondents were asked to indicate their level of agreement or disagreement with each affirmative statement presented, ranging from "strongly agree" to "strongly disagree".

Each group of the triad had its specific outline for the interviews. Thus, supervisors could share their perception on the alumni's work at Embraer, while the industrial advisors would discuss on the Master's thesis impact on the company.
The alumni's outline covered the identification of the respondent, the technology areas (EASN) in which their Master's theses were developed and their contribution to the work on their sector of the company and possible impacts on Embraer (if the results of their theses were implemented by the company).

The supervisor's interview outline consisted in both open and closed questions, covering the identification of the respondent, the contribution of their respective alumni's thesis to their work and to Embraer. The closed questions addressed the main contribution to the alumni's work in terms of quality, cost, time, rework and process.

The industrial advisor's outline covered the identification of the respondent and the possible impact of the Master's thesis results on the company (if implemented by Embraer). The possibility of the industrial advisors not being able to evaluate the work of the alumni on the company was also considered during the elaboration of the outline.

The results of the pre-test allowed the elaboration of the questionnaires of the second part of the case study research, which was conducted inside the company through an online platform (SharePoint). The questionnaires of Part 2 were also specific for each group of the triad. The alumni's questionnaire contained the identification of the respondent, the relation between the theme of the thesis and the alumni's work sector in the company, the implementation of the results of their thesis and the technology area in which the thesis was developed. The supervisor's questionnaire covered the identification of the respondent and closed questions on the contribution of the thesis to the professional maturity of the alumni, to their work and possible impacts on the company. The industrial advisor's questionnaire was composed of the identification of the respondent and closed questions on the possible impacts of the results of the thesis on Embraer. Also, there were closed questions on the contribution of the results of the thesis on the alumni's work at their work sector, if the advisor felt comfortable to answer that.

At the end of every questionnaire, there were some open questions so the respondents could make observations on their answers and include other aspects that were not mentioned in the interview outline.

\section{Results and Discussion}

\subsection{Embraer}

The present case study covered the three last PEE classes to finish their Master's theses, considering only the alumni who were still working at Embraer by the time the questionnaires were answered and also by their respective supervisors and industrial advisors, as shown in tab.1. It is important to notice that some supervisors and industrial advisors could have more than one employee or graduate student from these classes.

For the pre-test, 4 triads were selected based on some aspects regarding the alumni's performance and leadership skills shown throughout the program, their supervisor's experience in the company and their advisor's mentoring experience. 
Thus, the interviews covered the most qualified members of each group in order to obtain relevant data for designing the questionnaires of the second part of this case study.

Table 1 -Responses and total numbers of each group.

\begin{tabular}{|c|c|c|}
\hline Group & Responses & Total \\
\hline Alumni & 62 & 81 \\
\hline Supervisors & 27 & 58 \\
\hline Industrial Advisors & 32 & 47 \\
\hline
\end{tabular}

Out of the results obtained from the alumni's interviews, the main contributions from the Master's Program conclusion were related to aspects of personal and professional development, technical competence and networking. Possible impacts on the company would be the improvement of processes and products.

Based on the supervisors' interviews, the main contributions from the Master's Program conclusion to their employee's work were related to aspects of academic maturity, deeper knowledge related to the subjects of his/her work sector and technical competence. Some possible impacts on the company would be the development of new technologies and improvement of processes and products.

Finally, the results of the industrial advisors' interviews showed that the possible impacts on the company would also be related to the development of new technologies and to the improvement of processes and products.

The number of alumni who answered the second part of the questionnaire is presented in fig. 5 .

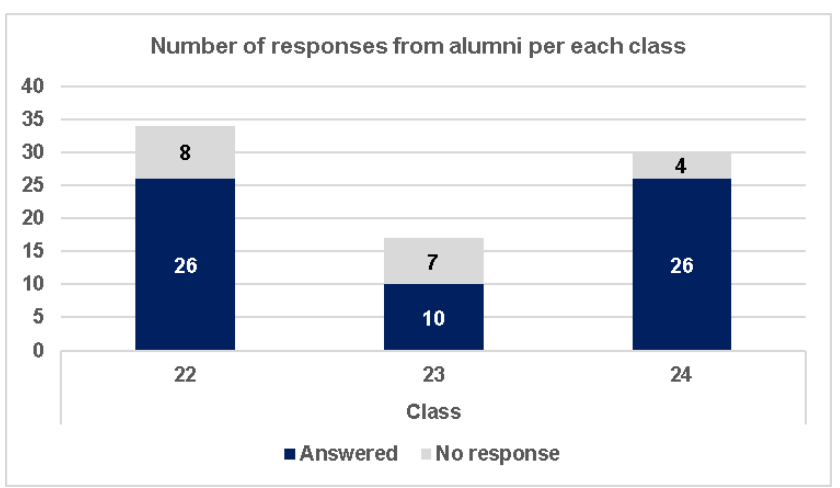

Figure 5 - Number of responses from alumni per each class.

\subsubsection{Alumni}

The results of the alumni's answers to the questionnaire of the second part of the present work are summarized in the following figures.

The technology areas [12] in which the Master's theses were developed are represented in fig. 6. These results are consistent with the fact that most of the engineers are enrolled in the tracks Systems and Structures. In addition to that, manufacturing processes are placed under the Aerostructures rubric.

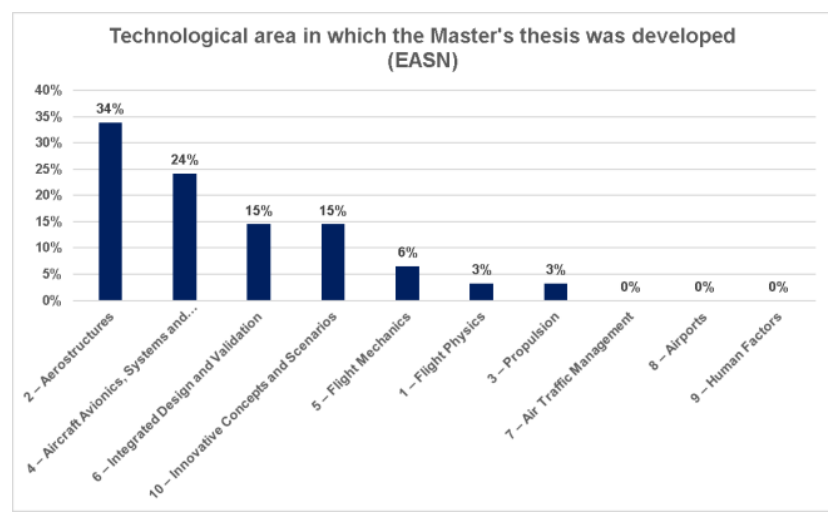

Figure 6-Technology areas in which the Master's theses were developed.

The alumni answers indicate that the majority of them, $71 \%$ actually, planned to acquire a Master's degree before joining the program. This result reinforces the claim that PEE is a strategy of attracting talented people to Embraer.

Fig. 7 shows that, under alumni perspective, the majority of the Master's results were not implemented in the company. Based on other surveys done by the authors with former students from PEE, from previous classes, there are two possible explanations for those answers. One is that it usually takes time for the ideas of PEE's alumni work to be implemented. Another possibility is that the results in terms of new technologies, processes, products etc. are much more related to individual development of the engineers, and not so much to the themes of their theses.

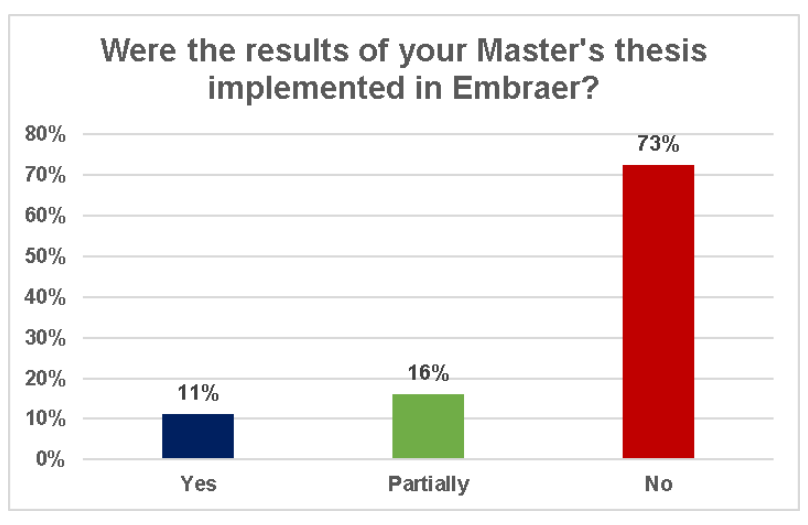

Figure 7 - Implementation of the results of the Master's theses in Embraer.

In terms of contributions of the Master's theses conclusion to the alumni's skills and competences, most of the respondents seem to agree on the improvement of their academic maturity, their knowledge of the company's work sector where they were allocated and their technical competence, as shown in fig. 8 . 


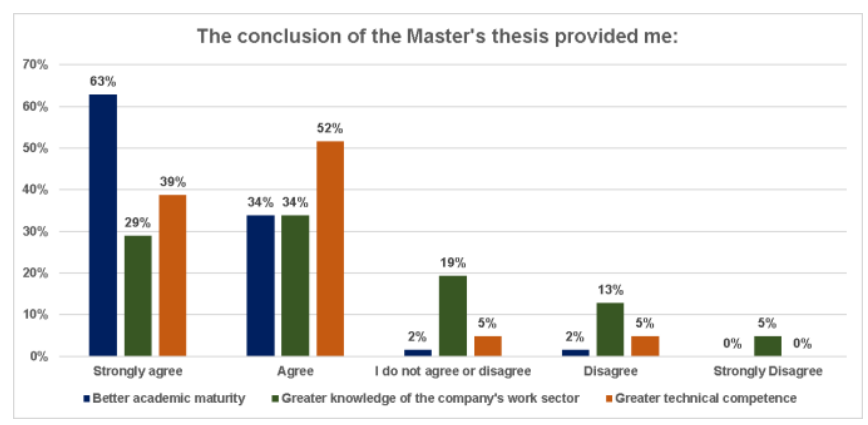

Figure 8-Influence of the conclusion of the Master's theses on alumni academic maturity and technical competency.

They also seem to agree on the contribution to their personal development and their networking, according to fig. 9.

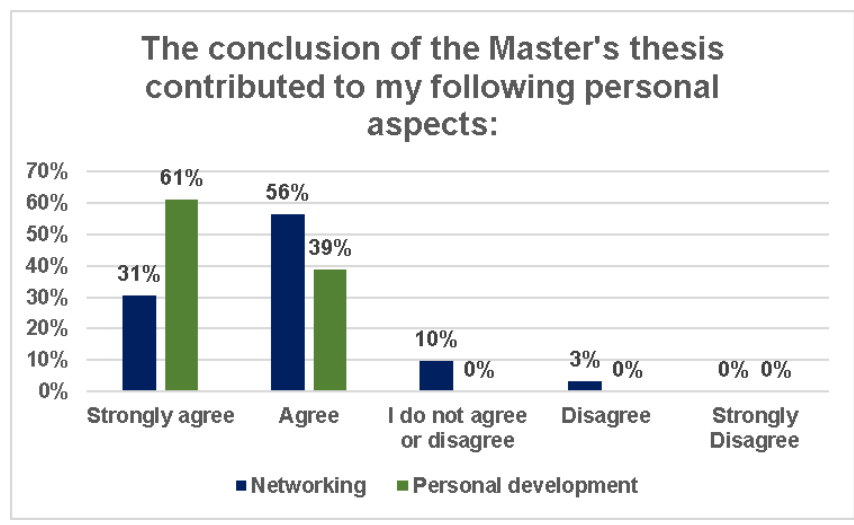

Figure 9-Contribution of Master's thesis on networking and personal development.

Fig. 10 shows that majority of the alumni agree that there was some contribution to the quality of their work. However, it also implies that most of them do not agree or disagree with contributions to rework reduction, decreased in time demanded or with process improvement.

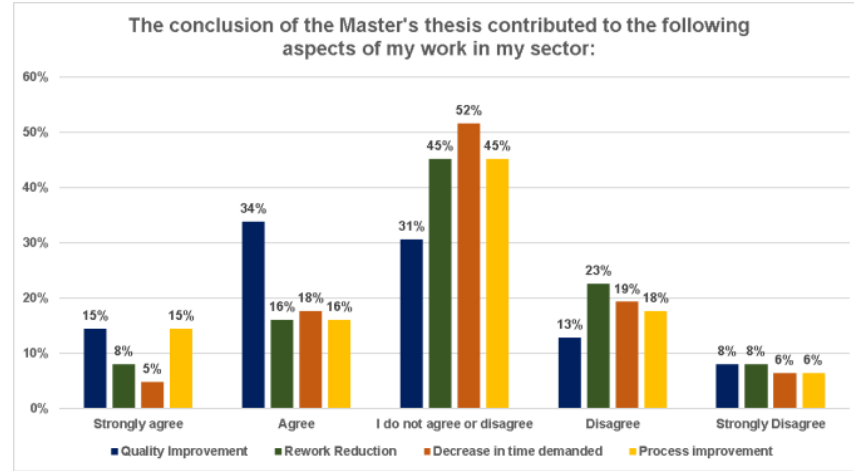

Figure 10-Contribution of Master's thesis to some aspects of alumni work.

Fig. 11 shows that the majority of the alumni agree that the results of their Master's theses would affect the company on aspects of development and mastery of new technologies, processes and products, though not so much on the development of services and patents.

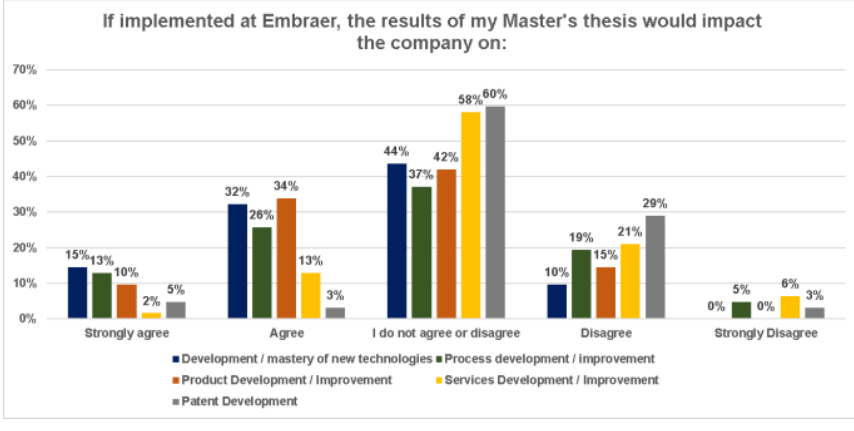

Figure 11 - Implementation of Master's theses on technology, process, product, service and patent.

Fig. 12 shows their perception on which Business Units of Embraer the results of their Master's theses would have impact.

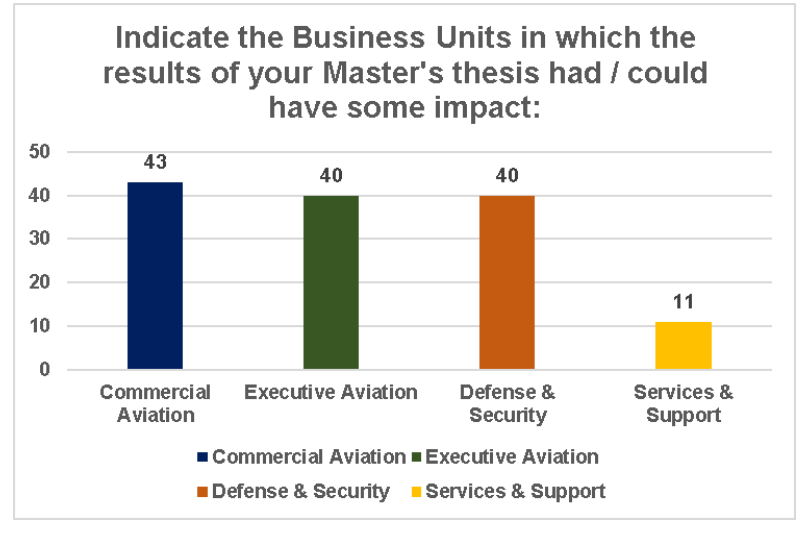

Figure 12 - Possible impact of the Master's theses on Business Units

It is interesting to observe that the perception of impact is evenly distributed, which is very much related to the fact that Embraer has a Chief Engineer organization to ensure harmonization of specialized personnel and knowledge among the different business areas.

Fig. 13 shows that the majority of the alumni developed articles in Congresses, Symposiums or similar and indexed journal articles related to their Master's theses.

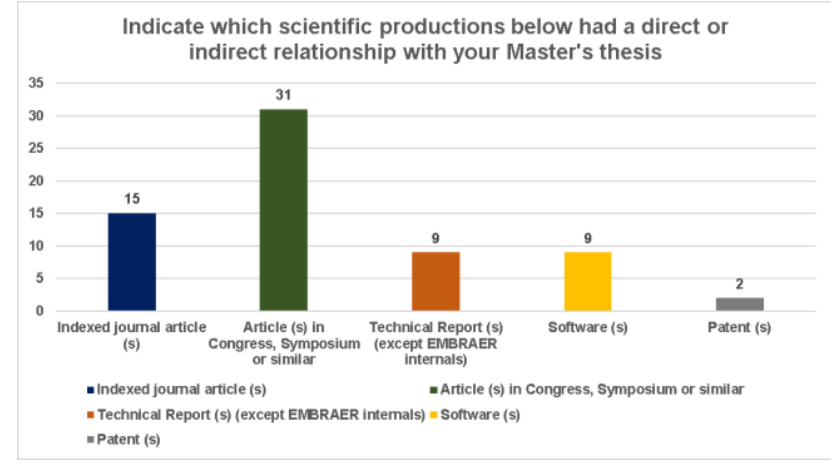

Figure 13 - Scientific productions as results of Master's theses

Results shown in fig. 13 are closely related to the metrics that Brazilian Ministry of Education uses to evaluate academic graduate programs in Brazil [13]. 


\subsubsection{Industrial advisors}

Fig. 14 shows that the majority of the industrial advisors agree that the better academic maturity, the deeper knowledge of the company's sector and the greater technical competence of their assisted alumni are the main contributions of the Master's Program conclusion.

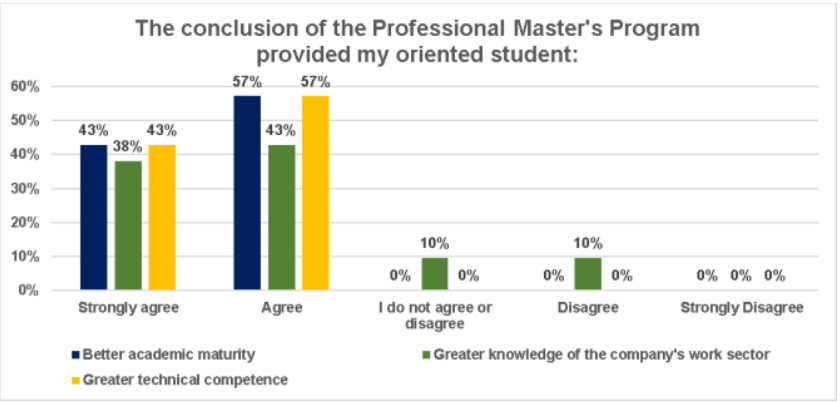

Figure 14 - Perception of industrial advisors on alumni competencies.

According to fig. 15, the majority of the industrial advisors agree on the contribution to the development and mastery of new technologies, processes, and products. However, it seems that most of them are not able to recognize the impact on patent development and do not agree on the services development / improvement.

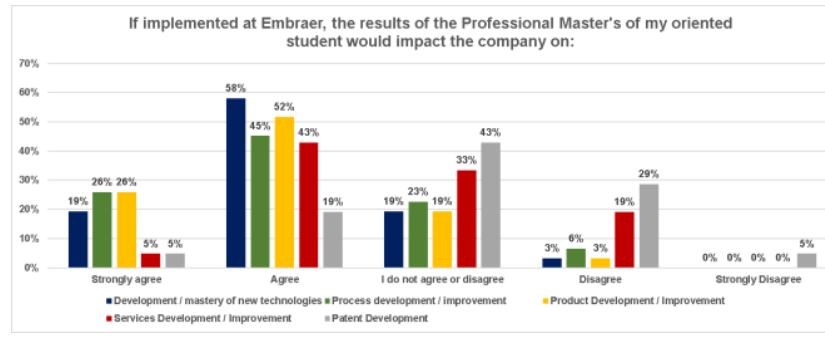

Figure 15 - Perception of industrial advisors on the impact of their Master's students work on the company.

\subsubsection{Supervisors}

In the context of this paper, supervisors are considered the students' direct managers after the company hires them. One of the most important roles of supervisors in leading their teams is to be aware of the level of competencies of his/her employees.

Fig. 16 shows that the majority of the supervisors agree that there were contributions of the Master's Program conclusion on their employee's academic maturity, knowledge of the company's sector and technical competence. Since the supervisors involved in this survey have other people under their command, this perception is even more important and precise than the alumni's opinion on the same topic.



Figure 16 - Direct supervisors' opinions on the results of the conclusion of the Master's Program on employee's competencies

Fig. 17 shows that the majority of supervisors agree with the contributions of the Master's Program to their employee's work in their sector, in terms of quality improvement, rework reduction and process improvement; however, there is a considerable number of respondents who did not agree or disagree with these aspects.

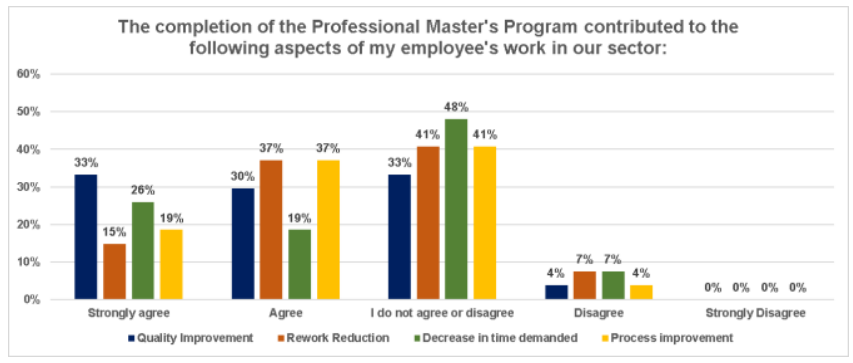

Figure 17 - Perception of supervisors on the contribution on the conclusion of his alumni Master's Program on their work.

Fig. 18 shows that the majority of the supervisors also agree that there would be some impact on Embraer in terms of technologies, processes and products. However, a considerable number of respondents do not agree or disagree with these aspects nor with the impact on services and patents. These results could be explained by the fact that Embraer is still a very "product oriented" company, and the culture that patents is new are much more related to the Technology Development sector than to Engineering areas.

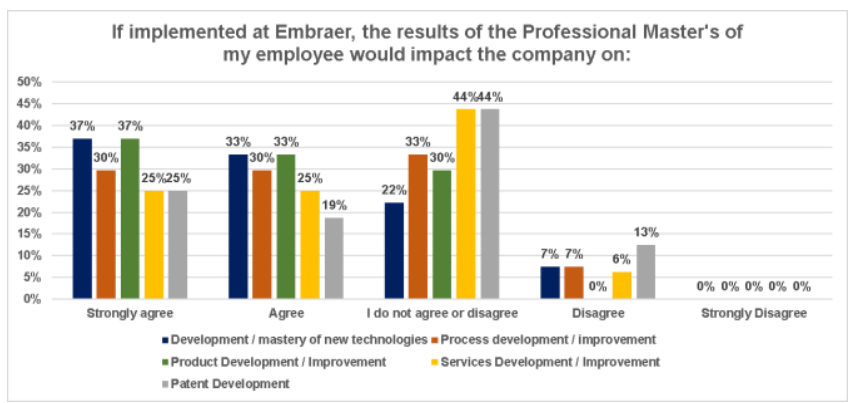

Figure 18 - Perception of Supervisors on the impact of their employee's Master's theses on the company as a whole. 
In general, the triads (student, industrial advisor and direct supervisor) agree that the conclusion of the Master's theses contribute to the engineers in terms of both technical skills as well as networking. It could also be observed that industrial advisors and supervisors are more positive with respect of impact on the company than the students are. This could be a consequence of their larger experience.

\subsection{ITA}

In order to evaluate possible impacts on ITA caused by the conclusion of the PEE Master's theses, a questionnaire was developed for ITA Faculty, who have been the most frequent academic advisors of the alumni of the program.

A pre-test was also carried out in this case study with the academic advisors from ITA. Professors responsible for the Management of the Master's Program were also interviewed so that the main aspects of impacts and contributions from the Master's Program conclusion on the Institute could be identified. Based on those results, a questionnaire was created with closed questions structured with Likert scale, covering impacts on the undergraduate engineering courses of the Institute, the research lines of the graduate programs and cooperative projects. Nine Professors have responded the survey.

Fig. 19 summarizes ITA Professors' perception on the influence of their participation in the Professional Master's program on the Institute. It is noticeable that none of the respondents disagree with the contributions to ITA. In addition, the majority of the Professors agree with the influences of the Master's Program on the conduction of their undergraduate courses, on their research lines in graduate programs and in cooperative projects involving FAPESP, FINEP, VINNOVA and others.

Some of the respondents claimed that their interaction with Embraer, during the development of the alumni's theses, allowed them to adapt the syllabus of their undergraduate courses according to the topics that were relevant for the company, in order to prepare the Engineering students to work in the Aeronautical Industry as a whole.

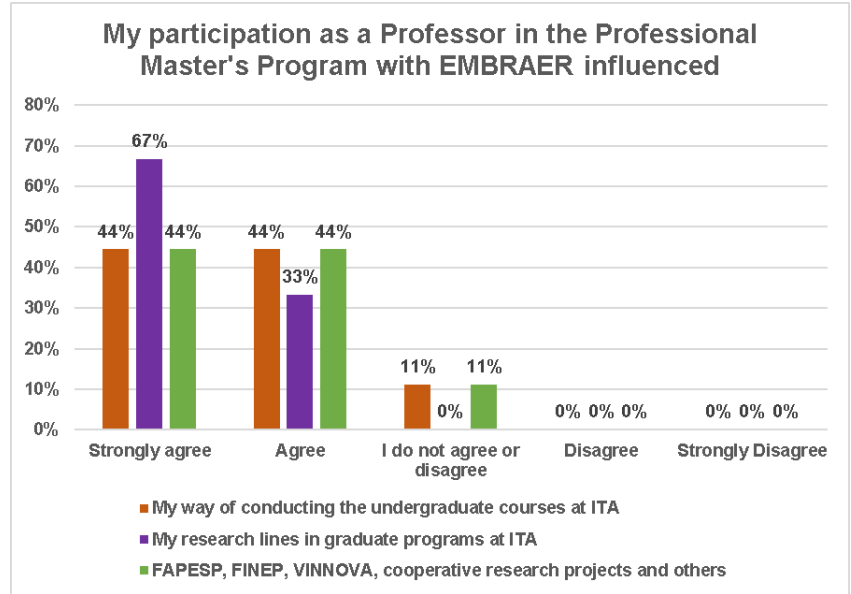

Figure 19-Perceptions of the influence of the Professional Master's Program on ITA.
Others have stated that their interaction with Embraer specialists highlighted the main technological challenges that are considered strategic for the Aeronautical field in the near future, hence influencing their research lines at ITA. In addition, some respondents have commented that their contact with the company through the PEE Master's Program brought them a broader view of the technological challenges of the Aeronautical sector and some maturity for proposing applied projects that were relevant.

At ITA, the majority of the respondents agree that since its creation in 2002, the professional Master's Program has had a strong influence on updating courses contents in the undergraduate level, to be more adequate to current challenges in Aeronautical areas. In the graduate level, working together with experienced people from the company (industrial advisors) provided them not only some interesting challenges, but also new ways of raising funds.

\section{Comments and Conclusions}

This paper was prepared to show some results about the perceptions of the most important stakeholders involved with the Master's Program in Aeronautical Engineering, on the students' development, on Embraer in terms of new technologies, processes, products, services and patents, and on ITA regarding education and research.

The presented results indicate that Embraer employees, as well as ITA Faculty, recognize that the Professional Master's Program (PEE) generated positive outcomes for both organizations.

Since the total retention rate (from all graduated classes) of PEE students as Embraer employees is around 50\%, it is reasonable to suppose that they have strong influence on the quality of products launched in the last decade, such as KC390, Praetors and E-2 Family [14]. A recent internal survey indicated that among the engineers who developed those planes, around $30 \%$ of them are PEE alumni.

ITA and Embraer have recently embarked on a new education initiative, an Academic Professional Doctorate, similar to PEE, in which the students also have two advisors (academic and industrial) whereas the dissertation should address a challenge proposed by the company and accepted by ITA. Funding support is shared between ITA and Embraer, and the company contributes to the student's scholarship.

\section{References}

[1] History of CTA, 2019. Available: http://www.iae.cta.br/index.php/history. [Accessed Jul 19].

[2] EMB 100 Bandeirante, 2019. Available: https://historicalcenter.embraer.com/global/en/emb-100bandeirante [Accessed Jul 19].

[3] Historical Aircraft of EMBRAER, 2019. Available: https://historicalcenter.embraer.com/global/en/historicalaircraft [Accessed in Jul 19]. 
[4] D. Andrade, S.F. Almeida, L.C.S. Goes, "Experience in Strategic Partnership: Professional Master's in Aeronautical Engineering, ITA-Embraer". COBENGE, 2003.

[5] R. K. Yin, Case Study Research and Applications: Design and Methods. Thousand Oaks: Sage Publications, 2017.

[6] D. Kirkpatrick and J. Kirkpatrick, Evaluating Training Programs - The Four Levels. San Francisco: Berrett-Koehler Publishers, 2006.

[7] P. Phillips, J. J. Phillips, R. D. Stone, and H. Burkett. The ROI Fieldbook - Strategies for Implementing ROI in HR and Training. Burlington: Butterwoth- Heinemann, 2007.

[8] The ROI Methodology in 10 Easy Steps - Application Guide. The ROI Insititute, 2013.

[9] CDIO Initiative, 2019. [Online]. Available: http://cdio.org/ [Accessed Jul19].

[10] CDIO Syllabus 2.0, 2019. [Online]. Available: http://cdio.org/benefits-cdio/cdio-syllabus/cdio-syllabustopical-form [Accessed Jul 19].

[11] P. Lourencao, F. Rosa and O. Resende. "Use of Conceive-Design Learning Environments to Prepare Engineers for the Development of Complex and Highly Integrated Aeronautical Systems". Proceedings of the 12th International CDIO Conference, Turku: Finland, 2016.

[12] Aeronautical Research and Technology Areas. Available: https://easn.net/research-technology-areas/ [Accessed Jul 19].

[13] Ministry of Education - Evaluation Criteria: http://www.capes.gov.br/avaliacao [Accessed Jul 19].

[14] Embraer's webpage - https://embraer.com/global/en [Accessed Aug 19] 